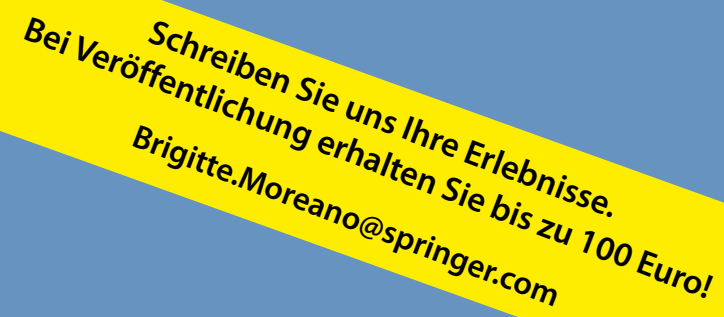

\author{
Ärztliche Erfahrung beschränkt sich nicht auf medizinisches Fachwissen. Sie \\ entsteht auch aus den mehr oder minder alltäglichen, heiter, ärgerlich oder \\ nachdenklich stimmenden Erlebnissen mit Patienten, Kollegen und Mitarbeitern. \\ Senden Sie uns Ihre Geschichte an: Brigitte.Moreano@springer.com. Für jeden \\ veröffentlichten Text erhalten Sie bis zu 100 Euro.
}

\title{
Ein schwerer Verlust
}

— Täglich wird man als Arzt mit schweren Schicksalen konfrontiert. Da ist es schon sehr erleichternd, wenn sich ein zunächst scheinbar trauriges Ereignis in eine eher heitere Episode umwandelt.

An manchen Tagen geht es in meiner ohnehin stark überlaufenen Sprechstunde zu wie in einem hektischen Emergency Room. Ich hatte gerade bei einem Schüler der gegenüberliegenden Berufsschule die luxierte Schulter adäquat versorgt, als meine Helferin diskret den Raum betritt und mir zuflüstert: „Kommen Sie bitte!”

Im Nebenraum erklärt sie mir, dass sich noch ein junger Mann, dessen Familie samt und sonders bei uns medizinisch betreut wird, angekündigt hatte, weil ein Familien- mitglied verstorben sei und er noch unbedingt in meine Sprechstunde möchte. Jetzt säße er schon in meinem Zimmer, fügte sie hinzu.

Ich eröffnete das

Gespräch, indem ich inm mein Beileid ausdrückte und fragte, wer denn verstorben sei.

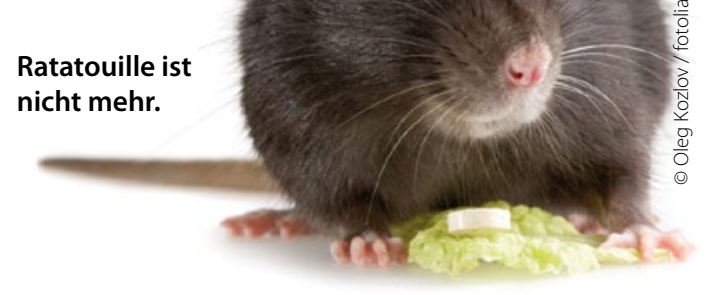

Der gefasst wirkende junge Mann erklärte etwas umständlich: „Ich glaube, den kennen Sie nicht. Hier ..." und dabei streckte er mir seinen rechten Zeigefinger entgegen, „hier hat er mich in seinem Todeskampf gebissen!" Irriert schaute ich auf die oberflächliche Bisswunde.

"Ja, ich bin fix und fertig, dass Ratatouille, meine Ratte, gestern von uns gegangen ist. Ich hab sie eineinhalb Jahre gehabt. Meine Freundin und ich sind fix und fertig. Mein Chef hat auch gesagt, ich soll mich für die Woche krankschreiben lassen".

DR. MED. JÜRGEN RABE, DREIEICH •

\section{Hausarzt als "Dienstleister"}

- Ich komme mal wieder kurz vor knapp zu unserer Praxis (mein 2-jähriger Sohn wollte partout nicht in die KiTa, sondern lieber auf den Hauptbahnhof und Züge anschauen). Es ist Donnerstag, und die Warteschlange reicht bereits vom Eingang der Praxis bis zur Straße, knapp 50m. Da fragt man sich schon: Sind wir eine Suppenküche? Gibt es etwas umsonst?

Aber den Anblick ist man bereits gewöhnt. Vor allem am Montag und Donnerstag ist die Warteschlange ausgeprägt. Montags kann man das Wochenende mit einer $A U$ verlängern und donnerstags sozusagen vorziehen, wenn man dem Arzt glaubhaft verkauft, dass man wirklich(!) krank ist.
Ich kämpfe mich also von hinten nach vorne zur Tür durch. Von allen Seiten viel sagende Blicke, hier und da ein freundliches "Guten Morgen“, was soviel bedeutet wie: „Bitte nehmen Sie mich zuerst dran, geht auch ganz schnell/bzw. mir geht es besonders schlecht."

Mit einem gekonnten Scheuklappenblick, der nur nach vorne auf Tür und Schlüssel gerichtet ist, strebe ich vorwärts und gelange gerade noch so in die Praxis, bevor mich die Massen von hinten fast überrennen.

Den ersten Patienten kannte ich noch nicht. Ich bin neugierig, wer das wohl sei. Er begrüßt mich gutgelaunt. Im Grunde sei er nicht krank, aber er sei solange nicht beim Arzt gewesen und wollte nun einige Fachärzte wegen diverser "Lappalien" aufsuchen: den Orthopäden wegen Knieschmerzen, den Dermatologen wegen unspezifischer Hautprobleme, den Urologen aufgrund von Vorsorgemaßnahmen. Bereitwillig stelle ich die Überweisungen aus. Erleichtert, dass es sich um einen "einfachen" Fall handelt, verabschiede ich ihn. Beim Hinausgehen fällt ihm noch ein haariges Anliegen ein: „Zum Friseur müsste ich auch mal wieder! Stellen Sie dafür auch Überweisungen aus?"

Soviel zum Thema: Der Arzt zwischen Heilberuf und Dienstleistung ....

DR. MED. B. J. 